\title{
Effects of Site of Blood Collection and Duration of Storage on Coagulation Factor V and Factor IX Levels in Fresh Frozen Plasma
}

\author{
R Loganathan*, Rajendra G Kulkarni, Rakhee Kar, B Abhishekh and Debdatta Basu \\ Jawaharlal Institute of Postgraduate Medical Education and Research, Puducherry, India
}

\begin{abstract}
Background: As per Indian drugs and cosmetic act \& rules 1945 (DCA), 1\% or 4 units/month of all components should meet quality control parameter. Aims and Objectives 1.) To assess the level of clotting factors FV and FIX in FFP. 2.) To identify the association between clotting factors FV and FIX in FFP with its mode of collection and storage.

Methods: This is a Cross sectional study design done for a period of 20 months. The comparison of the levels of clotting factors such as V and IX between the blood group were carried out by using independent students' one-way analysis of variance. All statistical analysis was carried out at $5 \%$ level of significance and p-value $<0.05$ were considered as significant. All statistical analysis was done using software IBM PASW statistics (SPSS) version 19.0.

Result: The present study was done at a south Indian tertiary care center from January 2016 to August 2017. Around 28,919 FFPs were assessed during this study period. On comparing factor levels between blood bank and camp site, there were no significant difference.
\end{abstract}

Conclusion: In our study, FV and FIX were maintained as per DGHS criteria.

Keywords: Factor V, Factor IX, Blood Bank and Camp Site, Fresh Frozen Plasma.

\section{Introduction}

Drugs and cosmetic act \& rules 1945 (DCA)-INDIA, states that $1 \%$ or 4 units/month of Fresh frozen plasma(FFP) prepared and stored should be checked for quality control parameter to prove blood components were prepared and stored appropriately. ${ }^{[1]}$

Fresh Frozen Plasma (FFP) is a blood component prepared at blood center, frozen and stored at $-30^{\circ} \mathrm{C}$ collection. ${ }^{[2,3]}$ Many blood centers rely on PT and aPTT for assessing the quality of FFPs which is a gross method. Studies have shown that gross assessment doesn't reflect the true quality and there is decrease in factors FVIII and FIX levels in FFP under different conditions of collection, transport, storage temperatures

Our Blood Centre relies on non-ancillary tests like PT/ aPTT for quality check of FFP. But the guidelines advice to check the levels of labile coagulation factors, routinely.

${ }^{[3,4]}$ Estimating coagulation factor levels would help us in preparation and storage evaluation process and hence the issues can be addressed. ${ }^{[3]}$

This study is conducted which helps in establishing coagulation factor assay and assess conditions which affects factor levels like collection, transportation, preparation procedure also time taken, storage conditions and issue of FFP.

\section{Aims and Objectives}

Primary objective is to assess the level of clotting factors FV and FIX in FFP and to identify the association of the levels of clotting factors in FFP with its mode of collection and storage.

\section{Materials and Methods}

The study was done in a south Indian tertiary care center for a period of 20 months from January 2016 to August 2017. This is a Cross sectional study design.

a. Inclusion criteria: FFP prepared from whole blood donations at our Blood Centre and voluntary blood donation camp site, with varying duration of storage but within 12 months.

b. Exclusion criteria: FFP units which are discarded due to various reasons like leaking bags, found positive for transfusion transmitted infections.

c. Number of groups to be studied: This study involves one group of FFP units prepared at our Blood centre. They were categorised into FFPs collected from blood Centre and at camp site.

Sampling population: FFP units available in the department of Transfusion Medicine.

Sample size calculation: sample size $n=155$, since no data is available on the level of clotting factors FV and FIX in 
our population, the sample size was given arbitrarily based on feasibility, logistics and budget. Standard guidelines advise minimum of $1 \%$ or 10 units of total FFPs prepared per month to be taken for factor assay.

Sampling technique: Convenient sampling.

Study procedure: FFP were prepared by PRP (platelet rich plasma) method of component preparation. Once components were prepared, FFP were frozen by keeping them in deep freezers of temperature $<-60^{\circ} \mathrm{C}$ and stored at a temperature $<-30^{\circ} \mathrm{C}$.

Sample collection and processing: On $3^{\text {rd }}$ day of every month 7 FFP units were selected from the month of January 2016 till August 2017 for a period of 20 months. $5 \mathrm{ml}$ of sample was collected from side tube in a plain tube after thawing in a water bath for 20 minutes at $37^{\circ} \mathrm{C}$, under sterile conditions and transported in cold chain to coagulation laboratory of haematology section under department of pathology within 2 hours and all samples are processed on the same day. In coagulation lab levels of various factors in FFP were determined.

Mode of Collection: Whole blood was collected at voluntary blood donation camp site and at Blood centre.

Mode of Transport: All whole blood collected at camp site were transported in cold chain boxes and FFP were prepared within 8 hours after collection.

Mode of Storage: FFPs were frozen in deep freezer at $-80^{\circ} \mathrm{C}$, after 24 hours and after TTI testing, all units were stored in deep freezer $<-30^{\circ} \mathrm{C}$.

Collection Time: Collection time was categorised into less than 4 hours and between 4 to 8 hours of FFP preparation.

Our issue of interest was to test the decrease in coagulation factor activity in FFPs collected from blood bank with that collected from camp site, to measure the fall in factor activity and to have a quality check on FFPs.

\section{Laboratory Analysis}

Factor assays: Factor assays were performed on a fully automated Sta Compact Stago Coagulometer

List of variables and their measurement methods with standardization techniques

a. Independent variables: Rh type

b. Outcome variables: Factor levels, age of the bag, temperature of storage, volume of the bag, mode of collection

c. Confounding and interacting variables: $\mathrm{ABO}$ group

\section{Statistical Analysis}

Data regarding Levels of various coagulation factors, Age of the bag, Volume of the bag, Temperature of storage, ABO group, $\mathrm{Rh}$ type and mode of collection where be collected every month for a period of 20 months. Data was collected from coagulation registered maintained in coagulation lab.

The distribution of categorical data such as blood group, $\mathrm{Rh}$ factor, age of the bag, mode of blood collection was expressed as proportions. The continuous data such as Factor level, volume of the bag was expressed as mean with standard deviation except for Factor IX. The comparison of the levels of clotting factors such as $\mathrm{V}$ and IX between the blood group were carried out by using independent students' one-way analysis of variance. The linear relationship between the level of clotting factor with age and volume of the FFP bag were carried out by using regression analysis. All statistical analysis was carried out at $5 \%$ level of significance and p-value $<0.05$ were considered as significant. All statistical analysis was done using software IBM PASW statistics (SPSS) version 19.0.

\section{Results}

The present study was done at a south Indian tertiary care center from January 2016 to August 2017. Around 28,919 FFPs were analyzed during this study period. We had collected blood units from 191 camps. There were two modes of collection from blood bank and from camp site. Totally $155 \mathrm{FFP}$ were subjected for quality control estimation.

Factor $\mathrm{V}$ levels were compared between different modes of collection (Blood bank and Camp site) using student's t-test, there were no significant difference ( $p$ value-0.614) found between blood bank and camp site collection. Mean value for factor V levels were found to be 104.16 IU and 107.36 IU in Blood bank and Camp site collectios respectively. The mean value for factor $\mathrm{V}$ levels were found to be 123.02 IU and 103.78 IU between components prepared before 4 hours and components prepared after 4 hours respectively. On comparing factor $\mathrm{V}$ levels between two different times of component processing using student's t-test, we did not find any significant difference ( $\mathrm{p}$ value- 0.063 ) in factor $\mathrm{V}$ level. The factor $\mathrm{V}$ levels between different storage periods were compared using the one-way analysis of variance (ANOVA) test and found to have no significant difference ( $p$ value-0.267). The mean factor $\mathrm{V}$ levels for different storage times are 113.78 IU, 103.35 IU, 107.12 IU and 94.62 IU for 1 month, 4 months, 8 months and 12 months of storage periods respectively.

Factor IX levels were compared between different modes of collection (Blood bank and Camp site) using student's t-test, there were no significant difference ( $p$ value- 0.953 ) found 
between blood bank and camp site collection. Mean value for factor IX levels were found to be 111.76 IU and 112.26 IU in Blood bank and Camp site collectios respectively. On comparing factor IX levels between two different times of component processing using student's t-test, we did not find any significant difference ( $p$ value-0.181) in factor $\mathrm{V}$ level. The mean value for factor $\mathrm{V}$ levels were found to be $127.49 \mathrm{IU}$ and $110.23 \mathrm{IU}$ between components prepared before 4 hours and components prepared after 4 hours respectively. The factor IX levels between different storage periods were compared using the one-way analysis of variance (ANOVA) test and found to have no significant difference ( $p$ value-0.877). The mean factor IX levels for different storage times are $113.92 \mathrm{IU}, 113.74 \mathrm{IU}, 113.01$ IU and 104.02 IU for 1 month, 4 months, 8 months and 12 months of storage periods respectively.

Table 1: Abstract of all Coagulation factors \& Fibrinogen with all variables in the present study.

\begin{tabular}{|c|c|c|c|c|c|c|c|c|c|c|c|}
\hline \multirow{2}{*}{$\begin{array}{l}\text { Coagulation Factors } \\
\text { (DGHS QC Level) }\end{array}$} & \multicolumn{3}{|c|}{ Time of preparation } & \multicolumn{3}{|c|}{ Blood collection site } & \multicolumn{5}{|c|}{ Period of storage } \\
\hline & \begin{tabular}{|l|}
$<4$ \\
Hours \\
\end{tabular} & $\begin{array}{l}4 \text { to } 8 \\
\text { Hours } \\
\end{array}$ & $P$ value & $\begin{array}{l}\text { Blood } \\
\text { Bank } \\
\end{array}$ & $\begin{array}{l}\text { Camp } \\
\text { Site }\end{array}$ & $P$ value & $\begin{array}{l}1 \\
\text { month } \\
\end{array}$ & $\begin{array}{l}4 \\
\text { month }\end{array}$ & $\begin{array}{l}8 \\
\text { month }\end{array}$ & $\begin{array}{l}12 \\
\text { month }\end{array}$ & $P$ value \\
\hline 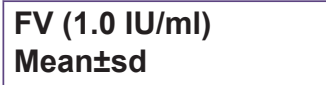 & $1.0+0.2$ & $0.8+0.3$ & 0.063 & $0.9+0.3$ & $0.9+0.3$ & 0.614 & $0.9+0.2$ & $0.8+0.3$ & $0.8+0.4$ & $0.8+0.4$ & 0.267 \\
\hline $\begin{array}{l}\text { F IX (1.0 IU/ml) } \\
\text { Mean } \pm \text { sd }\end{array}$ & $1.0+0.4$ & $0.9+0.4$ & 0.181 & $0.9+0.4$ & $0.9+0.4$ & 0.953 & $0.9+0.5$ & $0.9+0.4$ & $0.9+0.5$ & $0.8+0.4$ & 0.877 \\
\hline
\end{tabular}

Table 2: Studies comparing coagulation factor V.

\begin{tabular}{|l|l|l|l|l|l|}
\hline & \multicolumn{2}{|l|}{ Current study \pm SSD } & Dogra M et al & REMARKS \\
\hline Parameters & $<4$ hours & $>4$ hours & P value & $<8$ hours & \\
\hline $\begin{array}{l}\text { Factor V (IU/mI) } \\
\text { Mean } \pm \text { SD }\end{array}$ & $1.0 \pm 0.2$ & $0.8 \pm 0.3$ & 0.063 & $1.0 \pm 0.2$ & $\begin{array}{l}\text { Comparable and concordant } \\
\text { with our results }\end{array}$ \\
\hline
\end{tabular}

Table 3: Studies comparing various coagulation factors.

\begin{tabular}{|l|l|l|l|l|l|l|}
\hline & \multicolumn{2}{|l|}{ Current study } & $\begin{array}{l}\text { Naghadeh et } \\
\text { al }^{10}\end{array}$ & Agus N et al & $\begin{array}{l}\text { Standard haematology } \\
\text { reference ranges (SHR) }\end{array}$ \\
\hline $\begin{array}{l}\text { Coagulation } \\
\text { factors }\end{array}$ & $<4$ hours & $>4-8$ hours & P value & $<8$ hours & $<8$ hours & \\
\hline $\begin{array}{l}\text { F V (IU/ml) } \\
\text { Mean }\end{array}$ & 1.0 & 0.8 & 0.063 & 0.93 & - & $0.50-2.00$ \\
\hline $\begin{array}{l}\text { F IX }(\mathrm{IU} / \mathrm{ml}) \\
\text { Mean }\end{array}$ & 1.0 & 0.9 & 0.181 & - & 0.89 & $0.50-2.00$ \\
\hline
\end{tabular}

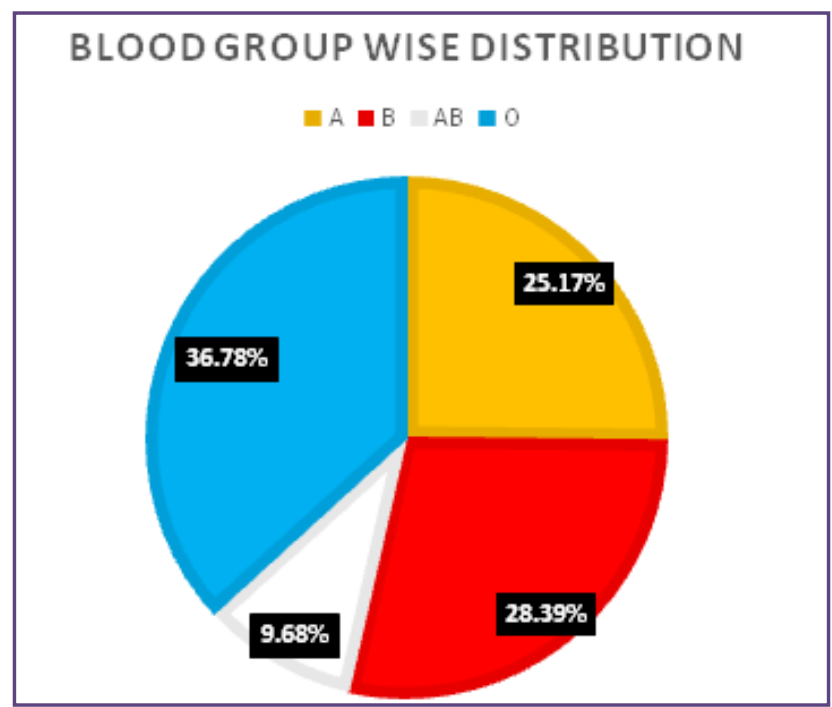

Fig. 1: Percentage distribution of FFPs with respect to ABO blood group. We had $39(25.17 \%), 44(28.39 \%), 15(9.68 \%)$ and $57(36.78 \%)$ FFP units in A, B, AB and 0 groups respectively. 


\section{Discussion}

FFP is a rich source of coagulation factor, it is always recommended to have total concentration of coagulation proteins estimated in the product.

As per DGHS criteria the ideal content of all coagulation factors (including Factor V \& IX) should be $1.0 \mathrm{IU} / \mathrm{ml}$ for one Unit FFP prepared from $450 \mathrm{ml}$ whole blood.

Abstract of all the coagulation parameters were summarized in Table 1. In FFP prepared between 4 to $8 \mathrm{Hrs}$ and on comparing with blood bank and camp site collection, FV and FIX nearly met the criteria. Factor V and factor IX levels were compared between blood bank and camp site collection, both showed that there is no significant difference in factor $\mathrm{V}$ levels and they were more than the minimum range by Standard haematology reference value. ${ }^{[5]}$ Factor V and IX levels were compared between two different time of component preparation and found to have no significant difference, both of their mean factor $\mathrm{V}$ levels were more than the minimum range by Standard haematology reference value. ${ }^{[5]}$ We did compare factor $\mathrm{V}$ and factor IX levels between different time periods of storage and found to have insignificant difference, all the mean values were more than the minimum range by Standard haematology reference value. Factor IX content in all groups were more than the quality required by NACO and NABH. ${ }^{[6]}$

In Canada a study done by Sheffield et al, where they shifted from PRP method to buffy coat method of component preparation. As it is known buffy coat method has 24 hours whole blood holding for increase platelet yield, this could affect plasma quality considerably. They compared the factor V, ABO matched factor VIII and fibrinogen levels with the retrospective data available on PRP method derived FFP and found factor VIII levels were decreased by 30 to 35 percentage. In our institute we have both PRP method and buffy coat methods of component preparation but we don't give 24 hours waiting period rather we give only 2 hours waiting period and doesn't have much effect on platelet quality. Our PRP method of FFP preparation can be compared with this study and no difference in Factor $\mathrm{V}$ was noted. ${ }^{[7]}$

One of the recent studies by Dogra et al in which they compared the factor V, factor VIII and fibrinogen levels between fresh frozen plasma and frozen plasma and between heavy spin and light spin derived fresh plasma and fresh frozen plasma. ${ }^{[8]}$ Our study is comparable with dogra et al, in terms of factor levels between FFP and FP, as shown in the below table. On comparing our study results with Dogra et al, it clearly shows that FFP which were prepared within 4 hours have more factor $\mathrm{V}$ levels, but all the three-time period have adequate factor $\mathrm{V}$ levels $(>0.7 \mathrm{IU} / \mathrm{ml})$. Huh YO et al also demonstrated that time donation has negligent effect on factor $\mathrm{V}$. ${ }^{[9]}$

In our study Factor $\mathrm{V}$ and Factor IX levels do not meet the quality control requirement by DGHS or European council guidelines. This can be attributed to poor storage conditions; in our Centre we do not use canister boxes to store FFPs rather FFPs are piled together due to lack of space which allows poor air current to the centrally stored FFP products. Other causes include maintenance breakdown which happens frequently in our Centre.

Our study was basically done to assess the coagulation factor content of plasmas obtained from two different source of collection like blood bank and camp site collection, since no baseline data were available on coagulation factor content of FFPs in this demography. Our study helped in establishing baseline data on coagulation factor contents in this demography. Our study also helped us to evaluate the quality required by different Indian guidelines like $\mathrm{NACO}$ and NABH. In India we are moving towards 100 percent voluntary blood donation program, which is not possible without conducting long distance voluntary blood donation camps and it is necessary to evaluate whether the components obtained from these long-distance camps were meeting the quality required by Indian guidelines. Our longest camp was to Thittakudi (Dr. Navalar Nedunzhelian College), which is $160 \mathrm{~km}$ from Puducherry towards south, and to Kolathur, Chennai towards north which is $165 \mathrm{~km}$ from Puducherry. We do conduct camps all over the season and our camps are more during summer season. Since south India is in a tropical region and we do experience extreme heat during April to June of every year, all these could affect the quality of plasma made in our Centre. Though we were not able to assess the season change that affects component quality, which is one of the drawbacks of our study, we were able to assess the FFP preparation process in total.

Efforts are being made to increase the time before plasma preparation to enable operational flexibility and to provide safer blood to patients for example male only plasma decreases the incidence of TRALI, in a developing country like India we are already having male only blood collection as most of our female donors are anemic and will be excluded from blood donation, our study results were also comparable for plasma components as in Table15. ${ }^{[10,11]}$ In our center we have a policy of not preparing plasma from multiparous female donors. The problem with plasmas processed after 8 hours is that they cannot be used for preparing cryoprecipitate which is used in hemophilia A. our plasma thus can be used for all clinical situations, 
including massive transfusion, disseminated intravascular coagulation, thrombotic thrombocytopenic purpura, liver diseases, etc.

Our center doesn't do donor plasma collection through apheresis even though our demand for plasmas are more than required and our whole blood processed FFPs are not sufficient to meet our demand, yet our FFP QC can be compared with the study by Runkel S et al, where they compared FFPs obtained by apheresis and by buffy coat method. Regular donors who donate through apheresis plasma donation have reduced Ig $\mathrm{G}$ levels and protein levels which cannot be substantiated in our study because of lack of resources and funding. We compared our factor levels with their study and found to have similar results in all the groups but apheresis plasma has more factor content in FFPs hence apheresis plasma is superior to both buffycoat derived and PRP derived plasmas. ${ }^{[12]}$

\section{Strength of the Study}

- It is the first of its kind done in south India.

- $\quad$ Factor V and IX were assessed, i.e. both stable and labile coagulation factors were assessed

- Various factors which affect coagulation factors (Heat labile) viz- Collection in blood bank and camp site, between various storage periods, blood groups etc. have been assessed, which has not been done earlier.

\section{Limitations of the Study:}

1. Fresh frozen plasma was not arranged in ideal conditions in the deep freezer and many a times it was over loaded.

2. Our Blood bank does not have Coagulometer all the study was done at Haematology Laboratory which was at a distance of 300 meters and samples had to be transported in ideal cold chain system.

3. Many samples could not be transported in ideal cold chain system box due to unavailability of the same.

4. Due to financial constraints the sample size as DGHS criteria (1\%) could not be met and was to be limited to 155 due to increase in basic price of kits (Consumables), taxes (VAT \& GST) and repetition of assay whenever the test showed invalid result.

\section{Conclusion}

In our study, levels FV and FIX were maintained as per DGHS criteria.

\section{Recommendations from our Study:}

1. Further studies have to be done to study efficacy of storing FFP in holed canister boxes which provides space for flow of proper cold air current with open overloaded storing as done in this study.

2. It is recommended to study the effect of interdepartmental assay systems like having a coagulation lab in every blood bank to do the minimal workup like quality control of plasma components vs transporting to other departments (to avoid sample transportation and delay in sample processing).

3. Studies have to be done to assess the effect of having back up deep freezers to store plasmas during equipment breakdown or maintenance.

4. FFP prepared from Whole blood collected from camps are as equal in quality compared with plasmas collected from blood centre and can be used for FFP preparation if FFP is prepared within 4 hours

5. Further studies have to be done to study efficacy of FFP prepared within 8 hours after transporting in Cold Chain transport boxes powered with battery backup.

\section{Acknowledgements}

I would like to thank pathology technicians and my coauthors for their help.

\section{Funding}

Intramural Rs 1,50,000/- and Self Rs 50,000/-.

\section{Competing Interests}

NIL

\section{Reference}

1. Fasano R, Luban NLC. Blood Component Therapy. Pediatr Clin North Am. 2008 Apr;55:421-45.

2. Chng WJ, Tan MK, Kuperan P, Wee Joo C. An Audit of Fresh Frozen Plasma Usage in An Acute General Hospital in Singapore. Singapore Med J. 2003;44:574-8.

3. Saran R. Transfusion medicine Technical Manual. 2nd ed. New Delhi: Directorate General of Health Services; 2003.

4. Arya RC, Wander G, Gupta P. Blood component therapy: Which, when and how much. J Anaesthesiol Clin Pharmacol. 2011 Apr;27:278-84.

5. Agus N, Yilmaz N, Colak A, Liv F. Levels of factor VIII and factor IX in fresh-frozen plasma produced from whole blood stored at 4 'C overnight in Turkey. Blood Transfus. 2012;10:191-3.

6. National AIDS Control Organisation. Standards for Blood Banks \& Blood Transfusion Services. Ministry of Health and Family Welfare. New Delhi; 2007. 1-101 p.

7. Sheffield WP, Bhakta V, Jenkins C, Devine D V. Conversion to the buffy coat method and quality of frozen plasma derived from whole blood donations in Canada. Transfusion. 2010;50:1043-9.

8. Dogra M, Sidhu M, Vasudev R, Dogra A. Comparative analysis of activity of coagulation Factors V and VIII and 
level of fibrinogen in fresh frozen plasma and frozen plasma. Asian J Transfus Sci. 2015;9:6-8.

9. Huh YO, Lichtiger B, Giacco GG, Guinee VF, Drewinko B. Effect of donation time on platelet concentrates and freshfrozen plasma. An in vitro study. Vox Sang. 1989;56:21-4.

10. Naghadeh HT, Roudkenar MH. A study of the quantity of some stable and labile coagulation factors in fresh-frozen plasma produced from whole blood stored for 24 hours in
Iran. Blood Transfus. 2009;7:39-42.

11. Mahida VI, Bhatti A, Gupte SC. Iron status of regular voluntary blood donors. Asian J Transfus Sci. 2008 Jan;2:9-12.

12. Runkel S, Haubelt H, Hitzler W, Hellstern P. The quality of plasma collected by automated apheresis and of recovered plasma from leukodepleted whole blood Stefan. Transfusion. $2005 ; 45: 427-32$.

*Corresponding author:

Dr R Loganathan, Blood bank, Super speciality block, JIPMER, Dhanvantrinagar, Gorimedu, Puducherry-605006.

Phone: +919566941313

Email: loganathanrajen@gmail.com

Date of Submission : 19/02/2020

Date of Acceptance : 06/09/2020

Financial or other Competing Interests: None.

Date of Publication : 30/11/2020 